\title{
Infrastructural Ubiquity: The Case of the Defense Highway and Space Complex
}

JEFFREY S. NESBIT

Harvard University

The design of infrastructure, and its systematic logistics, produces a ubiquitous rationality embedded in the appearance of politics. While the aesthetic and formal qualities of infrastructure can be criticized for being too rigid, focusing on functionality and structural performance, it is these very qualities that allow for its pervasive deployment. Not all architecture makes its appearance in this way. But, if we are to consider Mark Wigley's provocation that architecture is as much of a discursive project as a constructed or functional one, an architectural act appears to be a repeatable and evolving political imaginary. ${ }^{1}$ Architecture makes its appearance through the repetition of image, structure, and landscape-revealing a politic as opposed to engineered rationality. This paper explores the relationship between two disparate cases of U.S. national infrastructure; the defense highway and space complex. The study is not framed through modes of technological mobility-automobiles or rockets. Instead, this paper illustrates infrastructure through its national image, disguised by ubiquitous functionality. The U.S. defense highway and space complex describe an architectural process of state, national, and global scales. Built out of political imaginary, infrastructure projects itself through appearance, elegance, and ubiquity.

A veritable technological beyond, is not an inevitable consequence of scientific and technological progress; it is largely the result of the evolution of the politics of defense. ${ }^{2}$

-Paul Virilio, A Landscape of Events

\section{APPEARANCE}

Infrastructure has appearance. Although, its appearance is often overlooked. It is most readily understood as having no appearance-especially when its functions are operational. The repeatability of its performative and aesthetic qualities causes it to disappear. ${ }^{3}$ Paradoxically, its appearance is one of politics but disguised as function. National infrastructure is veiled by the image of state, space, and desire. All of which are projected through the functional object. Cultural theorist, Paul Virilio, speaks towards this kind of modernity by aligning it with perceptions of speed and technology. For Virilio, dualisms, such as city-to-country, no longer exist due to a shift from space towards time. ${ }^{4}$ Near and far have lost their meaning and the modern project is now governed by time, image, and network.

\author{
ERNEST HAINES \\ Harvard University
}

Desire to produce technological speed, reliability, control, and capacity manifest in a proliferation of images representing what infrastructure could or should be. Uniformity, standardization, and the materials of "dis-appearance" embed into the technological American landscape. They are constructed nationally and projected globally. David E. Nye, professor in history of technology at the University of Southern Denmark, most appropriately describes this projection. In his article, "Redefining the American sublime, from open road to Interstate," he claims:

Every form of [infrastructure] no matter how utilitarian it may seem, is implicitly part of an idealized landscape. It is not enough to look only at the vehicle and the pathway. Rather, each form of transportation has been used to define and construct a landscape, to embody a certain gaze. ${ }^{5}$

-David Nye, "Redefining the American Sublime, from Open Road to Interstate"

Nye employs the road, the canal, the train, and the interstate as simultaneously competing and progressing views of what the "idealized" American landscape is. The canal overtakes the early road, as it allows for continuous motion and comfort while providing picturesque appreciation for one's environment. The train overtakes the canal as it allows for greater speed and frequency without sacrificing the scenic nature of the voyage. The interstate overtakes the train as it mirrors a national desire for individuality without forgoing speed and safety. The politics of appearance are replaced when technology, and its subsequent infrastructure, allow for affordance to reflect national desires. Subsequently, as infrastructure progresses and is more technologically complex, it becomes standardized to a greater degree under state and national control. Increasingly siteless, infrastructural appearance is shaped by its associated repeatability. ${ }^{6}$ Technological progress, national control and repeatability are connected - they construct infrastructure's ubiquity.

\section{DEFENSE HIGHWAY AND SPACE COMPLEX}

The postwar engineers and managers whom we encountered are not rigidly committed to standardization. They tolerate, even embrace, heterogeneity. ${ }^{7}$

-Thomas Hughes, Rescuing Prometheus 


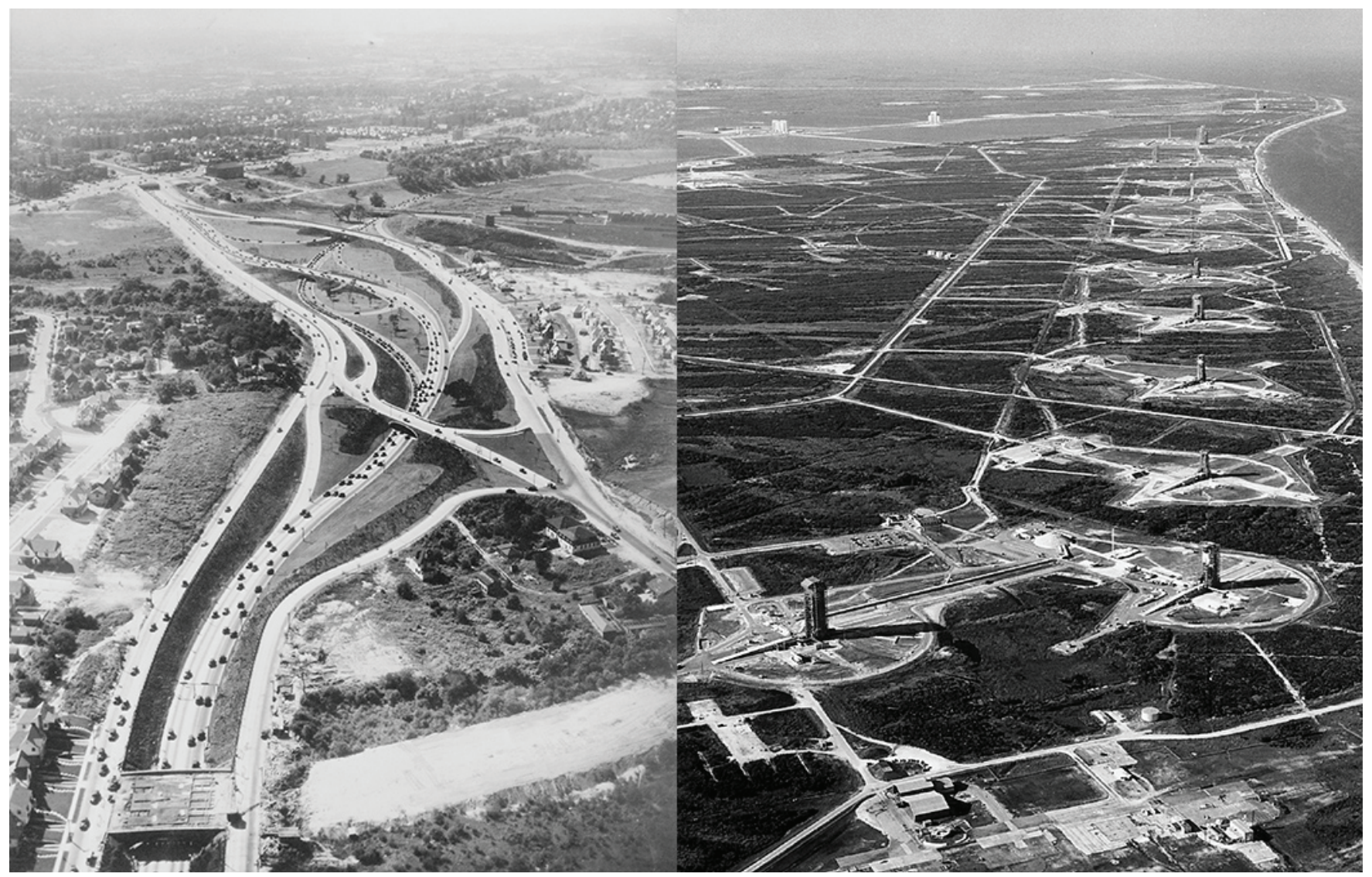

Figure 1. Kew Gardens Interchange, U.S. National Archives and Records Administration (left) and Missile Row, Cape Canaveral Air Force Station, 1964, NASA (right).

The National Interstate and Defense Highway Act (1956) and The National Aeronautics and Space Administration (1958) were established as responses to geopolitics and desired military strategies. ${ }^{8}$ They both enabled the construction of architectural and infrastructural features that were expressive of these politics. One connects a publicly accessible transportation system across the continent while the other explores extraterrestrial space and supports advancements in scientific technologies. They individually operate on different realms of space. One is terrestrial while the other deals with the earth's orbit and the extraterrestrial. They separately address different types of desire. Highways enable economic flows, technological speed, and public individuality while spaceports facilitate global surveillance, geopolitical territory, and place-based scientific exploration.

Yet, both the defense highway and space complex are constructs at scales and views from a national perspective. They display how infrastructure, when it is less tied to the form and image of the landscape, becomes constructive of it. This is not too disimilar from Paul Virilio's "aesthetic of disappearance." The desired speed of the nation, its capacity to mobilize and transfer resources, to monitor and exert control on the globe, produce a political appearance between nature, speed, and technology. This appearance, however, isn't bound to a single physical space. It empowers expansion and proliferation. In this way, by aligning the defense highway and space complex, difference doesn't necessarily exist. Instead appearances of an architectural act become tied to similar political intentionality.

Highways and spaceports both share ambitions of national identity. ${ }^{10}$ The desire for a national system of highways and a greater presence in space had been well established in the American imaginary. Realizing these desires came at an opportune moment in history. Dwight D. Eisenhower was president. He recognized mobility and technology were of national concern, proclaiming "the ability to convert swiftly from partial to all-out mobilization [was] imperative [for national]...security..." especially considering the development of new kinds of weapons and warfare. ${ }^{11}$ Russia launched Sputnik in 1957, marking a rise in The Cold War. This became a concern not only for military defense, but also an issue of national image. Sputnik posed a challenge to U.S. National supremacy in space. NASA was founded as a direct response to these concerns. In both cases, the image of a nation-its capacity to mobilize and develop technology-was invoked in the construction of infrastructure implicated and reliant on the American frontier landscape. 
The functional appearance of infrastructural sites such as the Kew Gardens Interchange or the launch complexes at Cape Canaveral (figure 1) resemble one another physically. These in turn resemble similar expressions of military and political power in other locations. They are systematic and rational; materialized as something concrete and static. Views enabled by the highway and the space complex, produce realized images of a nation. Its appearance can be attributed to their shared political aspirations. The view of the earth from space, or the view of a suburban landscape from an interstate, speak more to the political dimensions of space and time than the physical qualities of infrastructure. Infrastructure's form is subsidiary to the appearance of nation building.

General Motor's Futurama exhibit at the 1939 New York World's Fair can be viewed as having a national appearance. ${ }^{12}$ The exhibit described in the film To New Horizons radically transforms the physical and spatial qualities of American Life through infrastructural progress. With the introduction of high-speed multi-lane highways, agricultural production becomes more efficient, new perspectives of the landscape are experienced. New types of urban architectural form appear, resulting from the construction new infrastructure. The image of the national landscape is mechanical, rational, and systematic - the highway simply provides structure that enables cultural and political desires.

The nation expands into a global territory in the live broadcast of the first moon landing. The video feed of Buzz Aldrin and Neil Armstrong stepping out of Apollo 11 onto the lunar surface generate the expansion of infrastructural projection. The projection of national power at an unparalleled scale-a foot step and United States flag marked on the moon. Today, the image of NASA and space exploration are more widely accepted, national infrastructures facilitating the extraterrestrial politics are once again veiled. Only this time hidden by free-market capitalism.

\section{ELEGANCE}

Infrastructure has elegance. Its elegance embodies engineered precision and simplicity. Its form is rational and functional while also having an aesthetic. Formal qualities of infrastructure can be seen as banal, its architectural aesthetic separated from its rationality. This leads to a false dichotomy between infrastructure and architecture. However, contrary to common perspectives on infrastructural systems, its elegance is not only physical, it is discursive. Mark Wigley describes the tension between function and discourse within the architectural context in his essay "Resisting the City." He writes:

I want to insist that architects are first and foremost intellectuals... They don't make solid objects. They make discourse about objects... The real construction site is words...Programs could be devoted to characteristics of buildings that subvert the traditional mythology of the functional object, devoted, that is, to the irreducible strangeness of buildings. These are perhaps the qualities that secretly fascinate architects the most...Schools work hard to hide the fact that the heart of the discipline is doubt, enigma, paradox, and insecurity..$^{13}$

-Mark Wigley, "Resisting the City"

In contrast, stability and certainty are enduring traits fundamental to the typical concept of infrastructure-a proxy for the functional architectural object. Both bridges and buildings so they do not fall down. We expect they function reliably according to technical needs. Form and formation of the functional object follow its utility. However, as Wigley posits, utility in this circumstance is an unstable term, where discourse and politics shape the capacity to conceive of and speak about how or why it is useful.

This relates directly to architectural form, where elegance is incorporated within entire genealogies of type and aesthetic. The space that is formed and the styles that emerge get continually repeated. ${ }^{14}$ The proliferation of discourse about a particular archetype or style claims a particular kind of architectural appearance. The fact that there are selfsimilar arguments about a material construction justifies it as being the object of cultural production. And so infrastructural elegance becomes discursive. Its formal and political appearances are a standard deviation from one another and yet become part of a collective, material culture.

This is explored through two architectural features, the highway tollbooth and rocket service tower, framed by the defense highway and space complex. The tollbooth and the service tower are culturally produced materials; national infrastructures as examples of functional and political objects with technological elegance. Because both are situated into larger mechanized landscapes the highway's tollbooth and rocket's service tower become conceptually interchangeable. Their architectural features operate as infrastructural objects and as such, become emblematic of the infrastructures that host them.

\section{TOLLBOOTH AND TOWER}

Despite their utilitarian purpose, tollbooths quickly became associated with the experience of traveling the turnpike. Their hexagonal design underscored the streamlined travel that motorists experienced on the new, high-speed superhighway - which originally opened with no posted speed limit...toll collectors served as the "human face" of the new tolled roadway, and as its ambassadors, dispensing information on everything from interchange locations to weather conditions. ${ }^{15}$

- Curtis Miner, "The PA Turnpike: The Journey of the Irwin Interchange Tollbooth" 


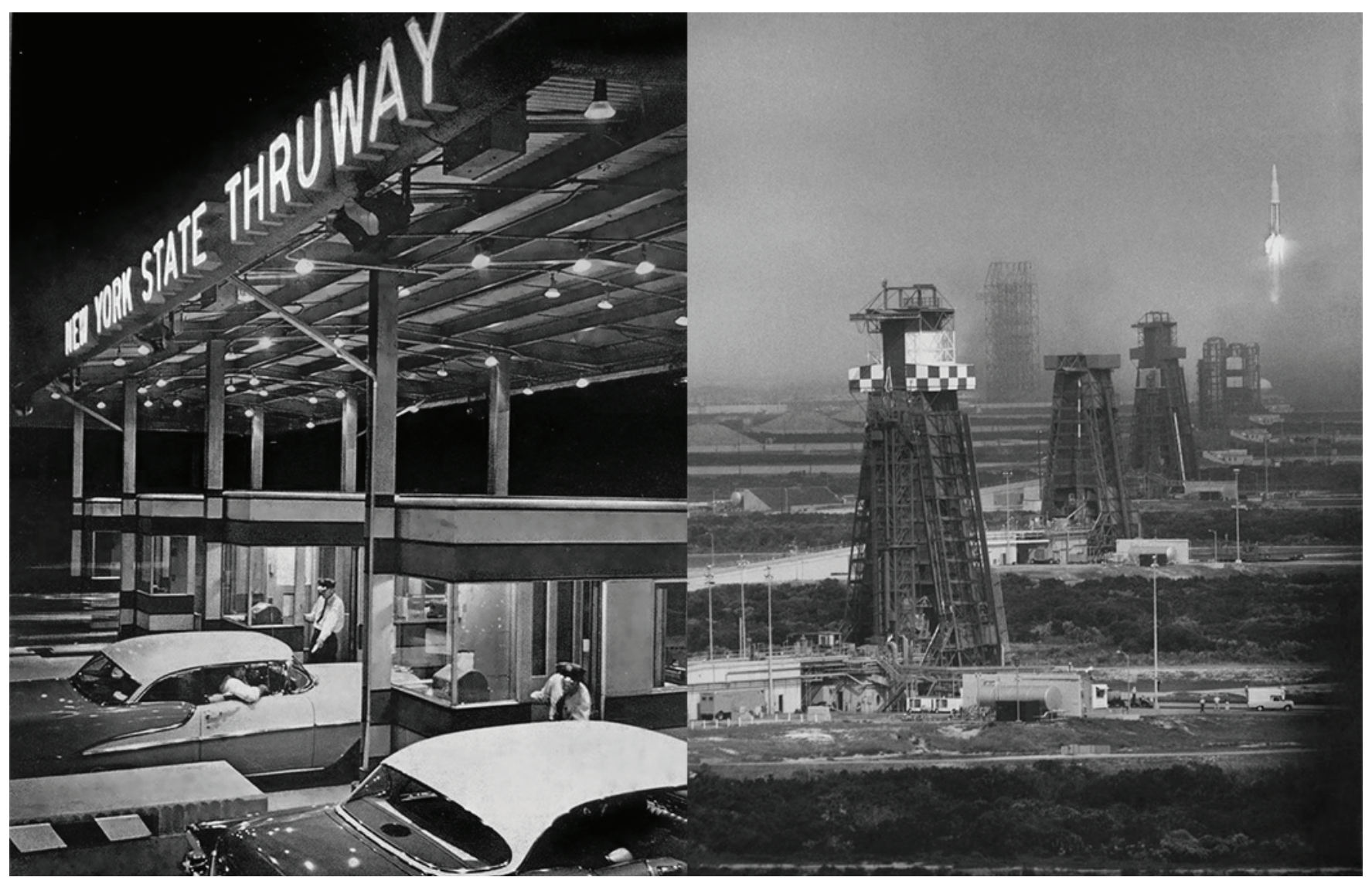

Figure 2. "Paying Tolls in 1956 on the New York State Thruway," National Geographic (left) and First Saturn V Rocket Launch, Cape Canaveral, Oct 30 1961, George Tames, New York Times (right).

Toll based limited access highways are an infrastructural type, the tollbooths that enable their function have architectural elegance. In a sense, the tollbooth is the toll highway-it creates limited access, it collects tolls for the highway's economic needs, and often is the first experience of its branding. For example, early tollbooth structures in the New York State Thruway (figure 2) proudly mark the naming of the highway. The number of tollbooth at each location relate to the expected amount of traffic. These tollbooths express appearance through engineered assemblage and aesthetic, while responding to a local environment. ${ }^{16}$

In this capacity, they distribute across the highway, simultaneously representing the highway as a political appearance and the tollbooth as a functional object. The standard deviation between their typological form comes as an expression of differentiating political appearances. Different turnpikes in different states, developed at different times. This comes up most clearly in the way their preservation is framed, as cultural artifacts. On the Merritt Parkway "the effort to save tollbooths wasn't only about the actual toll infrastructure... [it was] part of a longer fight to save the historic landscape... from being folded into a modern highway. ${ }^{17}$ The usefulness of the tollbooth, and the aesthetics that represent it, is cultural. It exists as a compound of different histories. Its elegance, and its discursive quality, stem from its political appearance.

The space complex service tower can be read similarly. Thomas Hughes, in the book Rescuing Prometheus, describes how "construction began on launching facilities at Cape Canaveral... before the engineers had a final design for the missile."18 The rapid pace of coordination along with large-scale systems management, offered a kind of technological embrace-a positive reliance on the elegance of technology. Needing to invent new organizational structures and planning, designs for the NASA Launch Operations Center (now known as Kennedy Space Center) strategically resisted conflict of communication between project groups. Construction of Launch Complex 18 was coordinated through the Army District Engineers on the Air Force Missile Test Annex. By March of 1956, the same year Eisenhower established the Defense Highway Act, it was determined the Viking service tower would be disassembled from the White Sands Proving Ground in New Mexico, transported to Cape Canaveral, and reassembled on schedule. It is not ironic how the speed and reliance on the defense highway is utilized. As the military became more decentralized, the launch site infrastructure could rely on the geographically remote goods because it was now linked by a defense highway, uniting the New 
Mexican desert and the southeastern Florida coastal wetlands. The architecture, representing the first attempts to expand territorial control into space, did not come from rationality. Instead, it came from a diverse collection of work by architects and engineers who expressed their own spatial awareness into the remote landscapes of launching rockets into space.

From the launch facilities at Cape Canaveral, to the largescale transformations of highway infrastructure, the nature of landscape in the 20th century emerged as an interactive system of mechanized processes. ${ }^{19}$ No longer was the sublime romance explicitly "machines in the garden." It now included a complete mechanized landscape of infrastructural elegance. ${ }^{20}$

By the 1960s, in the context of the landscape of space complex and tollbooth, human's devices and nature's mechanisms were more entangled than ever before. Buildings structured landscape, landscape performed as infrastructure, and infrastructure emerged in the form of the intensified elegance. The tollbooth and tower exemplify the capacity for networked systems to produce repeatable objects. They become an emblematic vision of material economies, gateways of power, and feed into a larger political appearance. The elegance of these systems comes out of attempts for rationality, coordination, precision, and simplicity.

\section{UBIQUITY}

Infrastructure distributes ubiquity. That is to say, infrastructure is formed through a standard deviation, hyperstandardized and overtly formalized. Being ubiquitous would imply these infrastructures are be best described as obvious, anonymous, and rational. However, it is their ubiquity, implicated in the role of politics, that generates power. This creates a return to Virilio and his exaggerated the view of modernity, vis-à-vis speed, technology, and war. For Virilio, urban architecture deals with "technological space-time" as networks are "no longer woven into the space of a constructed fabric, but into the sequences of an imperceptible planning of time in which the interface of man and machine replaces the facades of buildings and the surfaces of the ground." ${ }^{21}$

Technical objects are both singular and multiple. Sites become distributed physically and politically. The proliferation of infrastructural form, as well as its interchangeability, proves its discursiveness. For example, a discussion of the highway moves beyond its physical space. Naturally, it extends towards the sprawling suburban developments that stretch across the American landscape and the whole enterprise of big box stores. Like infrastructure, suburban developments in America are within a standard deviation of one another. The formal types and styles proliferate across the American landscape, and in a way, become a prominent image of the United States. ${ }^{22}$ An entire typology of national development made ubiquitous and legible through easily replicable appearance, only possible because infrastructure exists in particular ways (figure 3).
Whether or not architecture upholds the myth of the functional object, it unequivocally exists. It is simultaneously everywhere, and nowhere. It disguises political appearance as something legible and rational. The suburban home is America as these images of post-war consumerism propagated and mutated over time. Walmart, Best Buy, Home Depot are America and create an architectural representation of logistics; an automobility, distributed commodity, and the desire for efficiency. ${ }^{23}$ By relation, infrastructural objects like the highway's offramp or the space complex's launch pad are an image of America as well. And yet, their political appearances are hidden from the public view. They are seen only as functional objects, not functional objects that expand political diplomacy into processes of planetary urbanization, but aspirations for technological progress and militarization of the American landscape. It is infrastructure's capacity to distribute ubiquity, as seen in the offramp and launch pad, that generates the conditions for repetition of its political appearance.

\section{OFFRAMP AND PAD}

The marvelous mechanical devices of human beings are only a reflection of the mechanism of nature. ${ }^{24}$

—Le Corbusier, Aircraft

While the physical and functional qualities of these infrastructures present difference, the appearance of their politics unites them together. Their functional appearance is easily replaced by the representation of their political imaginary. For example, the "appearance" of space exploration and NASA doesn't come from the architectural or infrastructural shell, instead it derives from repeated imagery adopted from military-based operations. The physical resemblance and ubiquity of these systems, its legibility and uniformity, allow it to be a vessel for politicizing infrastructure. Sculptor and multi-media artist, Oliver Laric explores the relationality of culture in his work, particularly interrogating references to artifact and questions of originality present in material culture. Speaking towards this kind of appearance, in his film titled Versions the narrator says:

It is a frequent habit when I discover several resemblances between two things, to attribute to both equally even on points in which they are in reality different, that which I have recognized to be true of only one of them. Combined with this is another perversity, an innate preference for the represented subject over the real one. The defect of the real one is so apt to be a lack of representation. I like things that appear, then one is sure. Whether they are or not is a subordinate, and almost profitless question. ${ }^{25}$

-Oliver Laric, Versions 


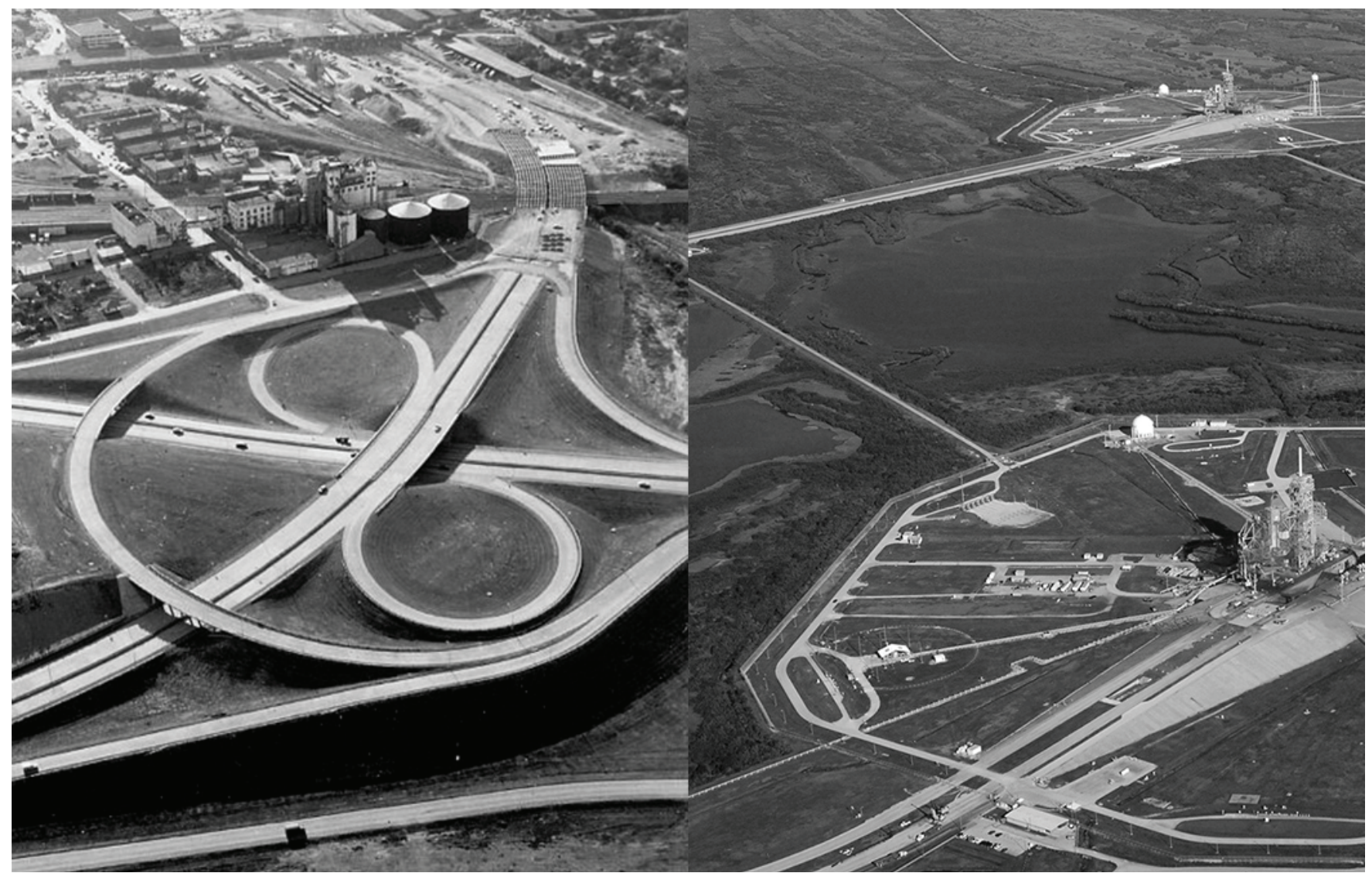

Figure 3. Aerial view of IH-35W looking south, with 183 intersection in the foreground, TxDOT (left) and Cape Canaveral Launch Complex 39A/39B, NASA (right).

With infrastructure, physical manipulations of technological progress and adaptation of the ground are ubiquitously repeated over vast lands. Though it is ever-present, this type of construction is often over looked. And yet, when considering the politics of appearance, it would be difficult to exclude them. The highway offramp and space complex launch pad are ubiquitous infrastructures. Variations of their formal type respond to political pressures, fiscal limits, or technological parameters. As they propagate across the landscape, they produce a ubiquitous material culture and continuous resource, both material and image.

Without the offramp, the interstate would not function as a networked system. It enables the interchange, which transfers flow from one highway to the next. Standardization is controlled by federal and state departments of transportation, and different forms appear-following requirements for safety, speed and efficiency. One variation of the offramp, the cloverleaf, has seen widespread adoption, adaptation, and evolution. First seen in the United States in 1928 in Woodbridge, N.J., it is an immediately recognizable type. So widespread that American historian, Lewis Mumford, once scornfully stated that "our national flower is the concrete cloverleaf." ${ }^{26}$
The evolution of launch site infrastructure is a way to decipher shifts in territory marked by launch site configurations. Pads manipulate the earth surface and directly inform a cultural landscape. Moonport, a NASA published document, tends to avoid providing derivatives of the decision-making process to cultural or design aesthetics. ${ }^{27}$ Only facts of construction, schedules, and procedural organization are described. When we compare the pads between 1957-1961 at the Soviet's site in Baikonur, to the U.S. pads at Cape Canaveral, we find significantly different infrastructure configurations for launch sequencing. Soviet's transported rockets horizontally on a rail, leaned its structural towers, and carved the pad into the ground, while the Americans transported vertically on the crawler, towers were constructed fully upright, and the pad was built up on an earth-formed podium.

Social interactions between groups of technology, military, and political position suggests these developments were not a "naturally" occurring practice in technology and science. As Launch Complex 17/18 at Cape Canaveral represent flexibility of the spatial politics, the infrastructure of launch pads themselves mark "visible systems, invisible processes, and indivisible scales" across the territory of human potentiality and actuality. ${ }^{28}$ By the time space shuttle launched on 
April 12, 1981, space exploration became ubiquitous, NASA became a bureaucracy, and its ambitions lost a cultural ability to attract the public's attention. Launch systems became infrastructural ubiquity.

The offramp and launch pad are thus depictions wrapped into a techno-spatial deployment of political and territorial modes, stretching their artificial boundaries through the cultural landscape in the United States. The technological landscapes of the defense highway and space complex can be seen as ecologies of political and spatial strategy. This would imply a convergence between military and ecology more broadly through the infrastructural features of material economy. ${ }^{29}$ Infrastructure in the remote might not only support, but also signify culturally, environmentally, and politically crafted transformations in architecture and urbanization. Infrastructure is a dispersion of mobilities. The militarization of infrastructure begs to question the relationality of power and artifact. Thus, it could be argued if conceptualization of tools and machines are expanded into urban space, crossing city-countryside divides, then processes of infrastructural urbanization are capable of rendering a hybridized world, entangled by militarized socio-technological culture. Embedded in processes of urbanization, the defense highway and space complex illuminate the politics of a national imaginary, hidden away in the repeatable ubiquity of the American infrastructural landscape.

\section{ENDNOTES}

1 Mark Wigley, "Resisting the City," in TransUrbanism, eds., Jake Brouker and Arjen Mulder (Rotterdam: V2, 2002).

2 Paul Virilio and Julie Rose, trans., A Landscape of Events (Cambridge, MA: The MIT Press, 2000).

3 Paul Virilio and Phil Beitchman, trans., The Aesthetics of Disappearance (Cambridge: MIT Press, 1991).

4 Paul Virilio, "Overexposed City," in Zone 1/2 (New York: Urzone, 1986).

5 David E. Nye, "Redefining the American Sublime, from Open Road to Interstate," in Routes, Roads and Landscapes, eds., M. Hvattum, et al. (Surrey; Burlington, VT: Ashgate, 2011).

6 See Keller Easterling, Extrastatecraft: The Power of Infrastructure Space (London: Verso, 2014).

7 Thomas Hughes, Rescuing Prometheus: Four Monumental Projects that Changed the Modern World (New York: Pantheon Books, 1998)

8 Dwight D. Eisenhower, "Annual Message to the Congress on the State of the Union." Online by Gerhard Peters and John T. Woolley, The American Presidency Project (H. Doc. 251, 83d Cong., 2d sess., 1954). https://www.presidency.ucsb. edu/documents/annual-message-the-congress-the-state-the-union-13.

9 Virilio and Beitchman, The Aesthetics of Disappearance.

10 Keller Easterling, Organization Space: Landscapes Highways and Houses in America (Cambridge, MA: The MIT Press, 1999).

11 Eisenhower, "Annual Message to the Congress on the State of the Union."

12 General Motors, "To New Horizons," promotional video presented at the "Highways and Horizons" exhibit at the 1939-40 New York World's Fair, 23:00. https://publicdomainreview.org/collections/to-new-horizons-1940/.

13 Wigley, "Resisting the City."

14 Easterling, Organization Space.

15 Curtis Miner, "The PA Turnpike: The Journey of the Irwin Interchange Tollbooth," The State Museum of Pennsylvania, April 19, 2016. http://statemuseumpa.org/ pennsylvania-turnpike-irwin-interchange-tollbooth/.

16 Miner, "The PA Turnpike."
17 Sarah Laskow, "The Case for Preserving the 20th Century Tollbooth," Atlas Obscura, March 31, 2017. https://www.atlasobscura.com/articles/ toll-booth-preservation.

18 Thomas Hughes, Rescuing Prometheus: Four Monumental Projects that Changed the Modern World (New York: Pantheon Books, 1998).

19 Hughes, Rescuing Prometheus.

20 Leo Marx, The Machine in the Garden: Technology and the Pastoral Ideal in America (New York: Oxford University Press, 1964); see also Virilio and Beitchman, The Aesthetics of Disappearance.

21 Virilio, "Overexposed City."

22 Easterling, Organization Space.

23 See Clare Lyster, Learning from Logistics: How Networks Change our Cities (Basel: Birkhauser, 2016); also see Jesse LeCavalier, The Rule of Logistics: Walmart and the Architecture of Fulfillment (Minneapolis: University of Minnesota, 2016).

24 Le Corbusier, Aircraft (The New Vision) (London; New York: The Studio Publications, 1935).

25 Oliver Laric, "Versions," MOV file, 09:06, December 2010. http://oliverlaric.com/ vvversions.htm.

26 Lewis Mumford, The City in History: Its Origins, Its Transformations, and Its Prospects (New York: Houghton Mifflin Harcourt, 1961).

27 See Charles Benson and William Barnaby Faherty, Moonport: A History of Apollo Launch Facilities and Operations, NASA Special Publication-4204 in the NASA History Series, 1978.

28 Pierre Bélanger, Ecologies of Power: Counter-Mapping the Logistical Landscapes and Military Geographies of the U.S. Department of Defense (Cambridge, MA: The MIT Press, 2016).

29 Bélanger, Ecologies of Power. 